FELIPE ROBERTO RODRIGUES

\title{
TÉCNICAS PARA FORMAÇÃO DE PRECEDENTES JUDICIAIS NO DIREITO PROCESSUAL CIVIL BRASILEIRO
}

\author{
Dissertação de Mestrado
}

Orientador: Professor Associado Dr. Antonio Carlos Marcato

UNIVERSIDADE DE SÃO PAULO

FACULDADE DE DIREITO

São Paulo - SP 


\title{
TÉCNICAS PARA FORMAÇÃO DE PRECEDENTES JUDICIAIS NO DIREITO PROCESSUAL CIVIL BRASILEIRO
}

\begin{abstract}
Dissertação apresentada à Banca Examinadora do Programa de Pós-Graduação em Direito, da Faculdade de Direito da Universidade de São Paulo, como exigência parcial para obtenção do título de Mestre em Direito, na área de concentração de Direito Processual, sob orientação do Professor Associado Antonio Carlos Marcato.
\end{abstract}

UNIVERSIDADE DE SÃO PAULO

FACULDADE DE DIREITO

São Paulo - SP

2018 
Rodrigues, Felipe Roberto

Técnica para formação de precedentes judiciais no direito processual civil brasileiro. São Paulo, 2018. 180p.

Dissertação de Mestrado - Faculdade de Direito da Universidade de São Paulo. Programa de Pós-Graduação em Direito.

Área de concentração: Direito Processual

Orientador: Professor Associado Antonio Carlos Marcato.

1. Procedure law; 2. Civil Procedure; 3; Precedents; 4. Democratic civil procedure 
BANCA EXAMINADORA:

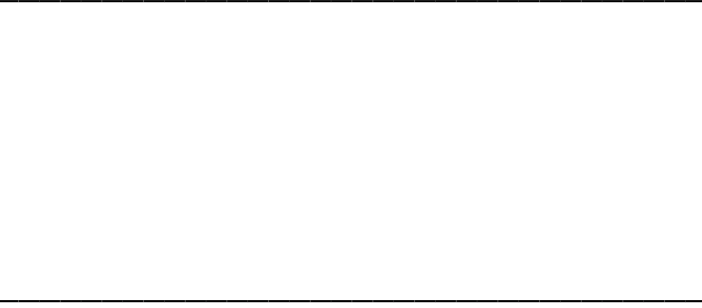


À Marcely,

Por acreditar em mim inclusive quando nem eu acreditava mais 


\section{AGRADECIMENTOS}

Agradecimentos são sempre arriscados, tendo em vista a enorme possibilidade de cometer injustiças com todos aqueles que, ao longo de todo o curso de pós-graduação, contribuíram com ideias, debates, materiais ou a mera compreensão da dedicação que o curso exigia. Ainda assim, ciente dos riscos, gostaria de agradecer nominalmente a algumas pessoas que foram fundamentais nessa jornada.

Em primeiro lugar, agradeço aos meus pais, João e Rosana, pelo apoio e incentivo constantes, que permitiram a busca pelo próximo degrau. Agradeço também à minha esposa, Marcely, e aos meus queridos Judith, Juvenal e Juca, pela paciência e pela dedicação que me permitiu concluir mais essa etapa.

Agradeço ao Professor Antonio Carlos Marcato pela oportunidade única de cursar a PósGraduação da Faculdade de Direito de São Paulo, pela orientação, disponibilidade e lições que muito contribuíram para meu desenvolvimento.

Agradeço aos Professores Carlos Alberto Carmona e José Carlos Baptista Puoli pelas valiosas ideias e críticas apresentadas no Exame de Qualificação, fundamentais para o desenvolvimento e correto enquadramento desse estudo.

Agradeço ao Professor Nelson Mannrich e à Professora Helena Abdo por me mostrarem o caminho a ser trilhado na Pós-Graduação. Igualmente, agradeço à Professor Elisabeth Vincentina de Gennari, pelo exemplo, abertura, e oportunidade única de acompanhá-la nas aulas da Faculdade de Direito de São Bernardo do Campo.

Agradeço aos meus chefes e colegas do MSV Advogados, entre os quais destaco Flávio Senra, Cristiane Pires e Ananda Palazzin, pela compreensão que me permitiu cursar a PósGraduação.

Agradeço aos inúmeros amigos que a Pós-Graduação me apresentou e aqueles que me permitiu reencontrar, destacando-se Hugo de Chacra Carvalho e Marinho e Bruno Leandro Palhares Perez, os quais, além dos debates de ideias, me ajudaram com valiosos subsídios de pesquisa.

Por fim, agradeço à comitiva de amigos que me apoiou e incentivou ao longo desses anos. Sem vocês, a vida não teria graça. 


\section{RESUMO}

Rodrigues, Felipe Roberto. Técnicas de formação de precedentes no Direito Processual Civil brasileiro. 2018. 180p. Dissertação (Mestrado em Direito) - Faculdade de Direito da Universidade de São Paulo, São Paulo.

Nessa dissertação, buscou-se examinar as técnicas de precedentes positivadas pelo Código de Processo Civil de 2015, suas inspirações, características e peculiaridades, especialmente a respeito da formação. A pesquisa partiu de um método dogmático para a investigação dos precedentes, examinando-os nos ordenamentos jurídicos em que foram inspirados, a experiência brasileira com técnicas similares e como se deu a importação e positivação no ordenamento jurídico pátrio. Ao final, procurou-se examinar as diversas formas de se permitir a formação democrática do precedente, à luz do contraditório e do devido processo legal, tendo em vista a característica própria do precedente brasileiro.

\section{Palavras-chave: .}

1. Direito processual; 2. Direito processual civil; 3. Precedentes; 4. Processo civil democrático 


\begin{abstract}
Rodrigues, Felipe Roberto. Precedents formation techniques in the Brazilian civil procedure law. 2018. 180p. Dissertation (Master Degree) - Law School, University of São Paulo, São Paulo, 2018..

In this study, the author seeked to analyse the precedents imported by the new Civil Procedure Code, the aims of the lawmaker, his inspirations and the traits of the new law. In view of that, the research investigated the brazilian precedents and the precedents in the common law countries. As well, the reaserch investigated the brazilian experience with precedents and the techniques developed and reunited by the Civil Procedure Code. In the end, considering the previous partial conclusions, the research was foccused in examinate if was a democratic way to create precedents in the brazilian techniques.
\end{abstract}

\title{
Keywords: .
}

1. Procedure law; 2. Civil Procedure; 3; Precedents; 4. Democratic civil procedure 


\section{SUMÁRIO}

SUMÁRIO

INTRODUÇÃO.

CAPÍTULO 1 - O PRECEDENTE JUDICIAL NOS PAÍSES DA COMMON LAW E

DA CIVIL LAW 6

1.1. O precedente judicial nos países da common law........................................ 6

1.1.1. Conceito de precedente e sua composição …............................................... 14

1.1.2. Técnicas de aplicação e afastamento dos precedentes .................................... 19

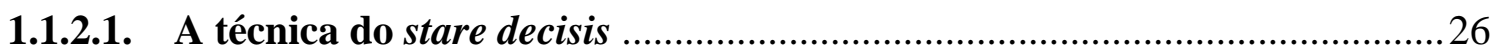

1.1.3. A ética dos advogados na formação e aplicação dos precedentes.................. 31

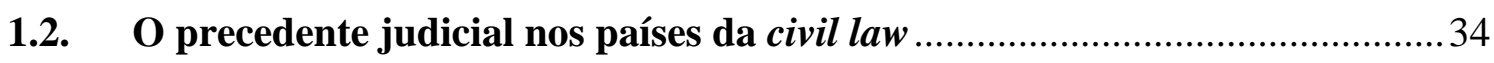

1.3. A aproximação dos sistemas da Civil Law e da Common Law ....................... 38

CAPÍTULO 2 - O PRECEDENTE JUDICIAL NO BRASIL ..................................... 43

2.1. Antecedentes históricos: o precedente judicial na história do direito

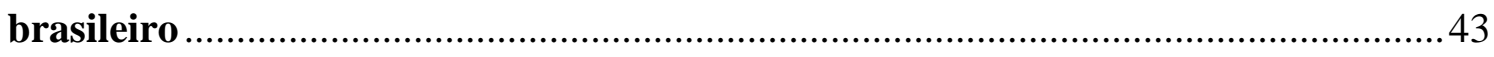

2.2. A crise dos Tribunais Superiores e do Poder Judiciário ...............................50

2.3. A valorização da jurisprudência e dos precedentes judiciais no Direito

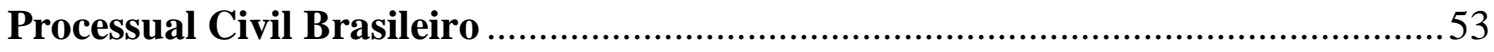

2.4. A tentativa de importação do sistema de Precedentes: o Código de Processo

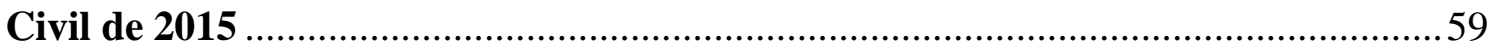

2.5. As reformas realizadas no âmbito da Justiça do Trabalho e a valorização da

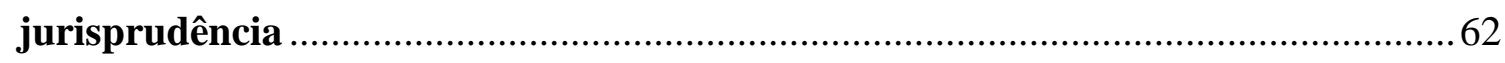

CAPÍTULO 3 - O SISTEMA DE PRECEDENTES BRASILEIRO ............................65

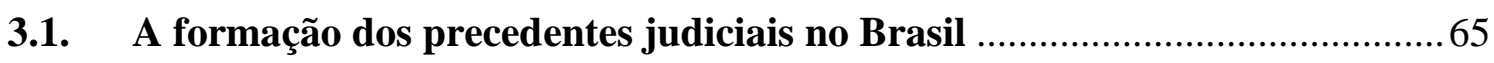

3.2. $\quad O$ rol de técnicas de formação de precedentes …........................................6 69

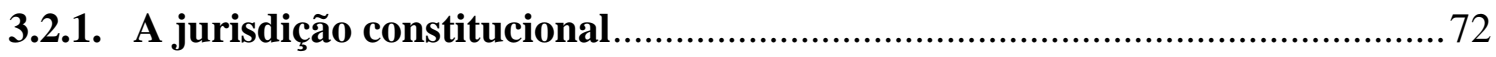


3.2.2. Os enunciados de súmula

3.2.2.1. Procedimento para criação, alteração ou revogação de enunciados de súmula 80

3.2.3. As técnicas de julgamento coletivo: litigância repetitiva 82

3.2.3.1. Recursos extraordinário e especial repetitivos

3.2.3.2. Incidente de resolução de demandas repetitivas

3.2.4. O incidente de assunção de competência

3.2.5. Os julgamentos em plenário ou no órgão especial 98

3.3. A vinculação aos precedentes previstos no art. 927 do Novo Código de Processo Civil 100

3.3.1. A reclamação constitucional como instrumento de vinculação 105

3.4. A posição do precedente judicial: fonte de direito?. 109

3.5. A constitucionalidade do art. 927 do Novo Código de Processo Civil 111

CAPÍTULO 4 - MICROSSISTEMA DE FORMAÇÃO DE PRECEDENTES 116

4.1. A formação dos precedentes como microcosmos do Estado Democrático de Direito116

4.2. A aplicação das técnicas de formação de precedentes

4.3. A participação popular na formação dos precedentes

4.3.1. A figura do amicus curiae.

4.3.2. As audiências públicas

4.3.3. A divulgação das ações: publicidade ampliada

4.4. A motivação no precedente judicial 128

4.5. As lacunas do Código de Processo Civil e 2015 e integração das técnicas para formação de precedentes

4.5.1. Positivação de atos processuais mínimos para a formação dos precedentes judiciais 135 
4.5.2. Os procedimentos para criação, revogação e revisão de enunciados de

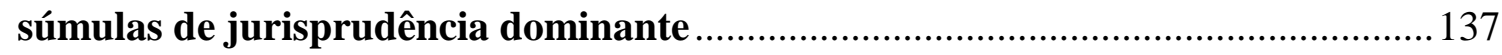

4.5.3. Publicidade ampliada e participação popular para fixação da tese............ 140

4.5.4. Critérios para a escolha de processos piloto ............................................ 141

4.5.5. A aplicação de regras diferenciadas de ética........................................... 145

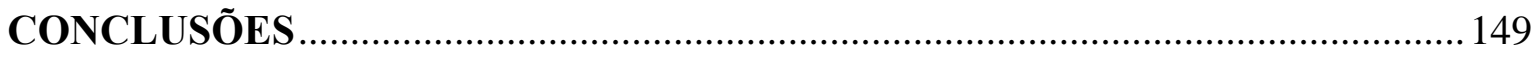

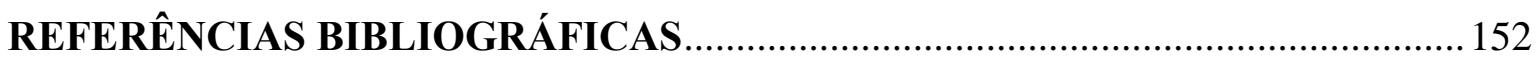

$\mathrm{X}$ 


\section{INTRODUÇÃO}

É característica comum aos estudiosos de processo civil, brasileiros ou não, o estudo de técnicas que possam vir a auxiliar no enfrentamento da crise do Poder Judiciário, de abrangência global. As razões da crise, conhecidas e já exaustivamente estudadas, compreendem tanto a conjuntura e dinâmica da sociedade a partir de meados do século $\mathrm{XX}$, quanto a abertura legislativa que se operou.

$\mathrm{Na}$ esteira das sucessivas reformas realizadas para esse fim, o legislador brasileiro elaborou um novo Código de Processo Civil para consolidar os avanços realizados na última década e tentar otimizar os resultados até então obtidos. Foram estabelecidos como objetivos a excessiva dispersão jurisprudencial, que chegou ao ponto de ser chamada de loteria, e o acúmulo de serviço, principalmente nos Tribunais de cúpula.

Entre as novidades do novo diploma processual, está a importação das técnicas de precedentes, as quais teriam o condão de capitanear essa virada contra a crise do Judiciário. Para tanto, foi concebida a vinculação às decisões proferidas sob determinadas técnicas e em determinadas circunstâncias. O precedente brasileiro, então, diferenciava-se daquele existente nos países da common law.

Apesar das diferenças e das peculiaridades da sistemática instituída, o legislador não primou pelo desenvolvimento e aprofundamento dos métodos de formação, a fim que as decisões atinjam os fins a que se destinam e tenham efetiva vinculação.

Nesse estudo, assim, será examinada a prática com precedentes normativos no âmbito da common law, a fim de extrair suas reais características, virtudes e deficiências, bem como se examinará a posição do Brasil no cenário jurídico mundial, tendo em vista a mudança realizada. Além disso, se examinará a tradição brasileira de valorização dos precedentes e as mudanças realizadas nas últimas décadas para este fim. Serão examinadas, então, as principais características das técnicas de formação de precedentes disciplinadas no art. 927 do Código de Processo Civil. 
Tendo em vista que a intenção desse estudo é examinar de forma ampla a formação dos precedentes e verificar como a sistemática poderia desenvolver sua performance, não serão tratados detalhes específicos de cada uma das técnicas do art. 927 do Código de Processo Civil, especialmente considerando que cada uma teria o condão de gerar um estudo equivalente a esse. Serão examinados os principais aspectos da (i) aplicação dos precedentes em cada uma das hipóteses do art. 927; e (ii) a problemática envolvendo a sua criação.

Ao final, além de tentar se compreender o que são os precedentes trazidos pelo Código de Processo Civil de 2015 e sua adequação ao ordenamento jurídico nacional, procurar-se-á examinar se há meios de lhes conferir maior efetividade e legitimidade perante a sociedade, adotando-se processos diferenciados, não concebidos para discutirem questões inter partes, mas como foros de debates de ideias para toda a sociedade. Afinal, a sociedade é a própria destinatária dos precedentes que serão criados. 


\section{CONCLUSÕES}

Passados por todos os pontos desse estudo, foi possível examinar a forma de aplicação dos precedentes nos países da common law, as regras rígidas de vinculação aos precedentes, bem como os problemas que são enfrentados na hipótese de os Juízes não concordarem com a decisão a ser aplicada. Igualmente, foi possível examinar outros sistemas jurídicos da civil law que também atuam com precedentes, ainda que não vinculantes, e o movimento global de convergência, com adaptações específicas nas peculiaridades próprias de cada um dos países.

Da mesma forma, foi possível verificar que o manejo de precedentes, no Brasil, não é uma novidade, sendo que desde o período do Império há regras jurisprudenciais que devem ser observadas pela sociedade. À evidência, há profundas mudanças de paradigma entre os precedentes antigos e os atuais, notadamente com relação à sua autoridade, sendo que tal evolução decorre, naturalmente, da própria evolução da sociedade. O processo civil brasileiro, da mesma forma, valoriza cada vez mais os precedentes, de modo a conferir estabilidade e previsibilidade ao ordenamento jurídico. Com esse mote, o Código de Processo Civil de 2015 foi promulgado com a intenção de reduzir a divergência jurisprudencial e enfrentar o absurdo número de ações judiciais em curso.

Porém, à luz da experiência estrangeira, é possível afirmar, com segurança, que os precedentes não conferem, por si só, estabilidade ao sistema. Os precedentes apenas mudam a forma de argumentação jurídica que usualmente era realizada no Brasil, sendo que os operadores do direito também deverão estar a par dos precedentes que venham a ser proferidos. Contudo, os precedentes permitem interpretação e, por esse motivo, também permitem uma dose de subjetivismo. Como assinala NeIL DuXbury, a doutrina de precedentes vinculantes é apenas uma ilusão ${ }^{408}$.

Os precedentes, embora tornem mais difícil a divergência jurisprudencial, não solucionam o caso. É a cultura do precedente que deve ser instituída no país e do

\footnotetext{
${ }^{408}$ DUXBURY, Neil. The nature and authority of precedent. New York: Cambridge University Press, 2008, p. 79;
} 
enfrentamento dos litigantes repetitivos, de modo a tornar desvantajosa economicamente a manutenção de milhões de ações no Poder Judiciário, congestionando-o.

Não se espera, porém, que essa cultura se desenvolva sozinha. A instituição do regime dos precedentes é salutar por ser uma tentativa de solucionar a crise. Contudo, a formação dos precedentes deveria, a nosso sentir, ter sido melhor concebida para o fim de trazer maior legitimidade às decisões que serão proferidas em cada uma das técnicas.

Dentro do modelo constitucional de processo adotado pelo Brasil, no parece que a forma mais efetiva para tanto seja a possibilidade de participação democrática da população nas técnicas de formação de precedentes, de modo a fixar normas plurais, com a influência do maior número de atores possível.

Considerando que a motivação é resultado do contraditório, se este for valorizado, o precedente será legítimo (em razão da participação) e sólido (em razão da motivação exauriente), conferindo a estabilidade que tanto se busca.

Dadas as características do país, bem como a inexistência, de fato, de um modelo federalista, não se acredita na viabilidade de que a formação dos precedentes seja feita caso a caso. A dispersão de entendimentos, nesse cenário, seria ainda maior e agravaria a situação jurídica vivida no país.

Assim, resta examinar formas de, no rol previsto pelo legislador, possibilitar a participação da sociedade, tal qual já é feito nas ações mais sensíveis do controle de constitucionalidade, como o julgamento do Supremo Tribunal Federal a respeito da possibilidade aborto de fetos anencéfalos.

Seria inocência imaginar que tal participação se daria em todos os julgamentos, inclusive naqueles de menor interesse. Contudo, deve ser conferida a possibilidade de participação, aqui compreendida como ônus da sociedade. Para que tal ônus seja atribuído à sociedade, esta deve ter ciência de que o julgamento está em andamento e que poderá afetá-la. Da mesma forma, sua participação não deve ser complexa e mereceria ser viabilizada pelas audiências públicas ou, desde que demonstrada a representatividade adequada, por meio da intervenção de amicus curiae. 
Por fim, ao final desse estudo foram apresentadas propostas de desenvolvimento da formação democrática do precedente, de modo a garantir igualdade de armas e isonomia entre os participantes. Na medida em que os precedentes vincularão, as partes devem estar em igualdade de condições para poderem influenciar o seu resultado.

Não se deve admitir, sob a égide de precedentes normativos, a existência de litigantes-sombra. O processo civil, nas célebres palavras de Cândido Rangel Dinamarco, deve servir de microcosmo da democracia, tendo em vista se tratar de exercício de poder, potencializado nos casos de vinculação. 


\section{REFERÊNCIAS BIBLIOGRÁFICAS}

ABBOUD, Georges. Súmula vinculante versus precedentes: notas para evitar alguns enganos. In: Revista de Processo, volume 165. São Paulo, Revista dos Tribunais, 2008.

Precedente judicial versus jurisprudência dotada de efeito vinculante - A ineficácia e os equívocos das reformas legislativas na busca de uma cultura de precedentes. in WAMBIER, Teresa Arruda Alvim (coord.). Direito e Jurisprudência, São Paulo: Ed. Revista dos Tribunais, 2012

. Do genuíno precedente ao stare decisis brasileiro: os

fatores histórico, hermenêutico e democrático que os diferenciam. In: Precedentes. Salvador: JusPodivm, 2015,

; SCHMITZ, Leonard Ziesemer; LUNELLI; Guilherme.

Como trabalhar - e como não trabalhar - com súmula no Brasil: Um acerto de paradigmas, In: Direito Jurisprudencial, vol. II, Coord: WAMBIER, Teresa Arruda Alvim, MARINONI, Luiz Guilherme; MENDES, Aluísio Gonçalves de Castro. São Paulo: Revista dos Tribunais, 2014

ABRAMOWICZ, Michael. Defining dicta. in: George Washington University Law School, 57 Stan, L. Rev. 853, 2005, p. 104.

ALEXY, Robert. Theorie der juristinchen Argumentation (tradução de Hutchinson Schild Silva: Teoria da argumentação jurídica), $2^{\text {a }}$ edição, São Paulo, Landy Livraria e Editora Ltda., 2005.

; DREIER, Ralf. Precedent in the Federal Republic of Germany. In: Interpreting precedents. A comparative study. New York: Routledge, 1997, p. 24

ALVES DA SILVA, Paulo Eduardo. Gerenciamento de processos judiciais. 
ANDREWS, Neil. Influência europeia sobre o processo civil inglês: a Inglaterra não é mais uma ilha, in Revista de Processo, volume 195, ano 36, maio de 2011.

ANDRIGHI, Fátima Nancy. Recursos repetitivos, in Revista de Processo, volume 185, São Paulo, Revista dos Tribunais, 2010.

ANGELL, Ernest. The amicus curiae: American development of English institutions. International and Comparative Law Quarterly, vol. 16, p. 1017-1044, out/1967

ARAÚJO CINTRA, Antônio Carlos; GRINOVER, Ada Pellegrini; DINAMARCO, Cândido Rangel. Teoria Geral do Processo. 23. ed. Malheiros, 2007.

ARRUDA ALVIM NETO, José Manoel de. A EC n. 45 e o instituto da repercussão geral, Reforma do Judiciário - Primeira reflexões sobre a Emenda Constitucional n. 45/2004. Obra coletiva coordenada por Teresa Arruda Alvim Wambier, Luiz Rodrigues Wambier, Luiz Manoel Gomes Jr., Octavio Campos Fischer e William Santos Ferreira. São Paulo, Revista dos Tribunais, 2005, p. 63 a 99.

ARRUDA ALVIM WAMBIER, Teresa. Precedentes e evolução do direito, in Direito Jurisprudencial. Teresa Arruda Alvim Wambier, coordenação. São Paulo: Editora Revista dos Tribunais, 2012.

Recurso especial, recurso extraordinário e ação rescisória. 2. ed. São Paulo: Editora Revista dos Tribunais, 2008. . Súmulas e inadmissibilidade da apelação, Terceira etapa da reforma do Código de Processo Civil. Estudos em homenagem ao Ministro José Augusto Delgado. Obra coletiva organizada por Adriano Caldeira e Rodrigo da Cunha Lima Freire, Salvador, Editora Podvm, 2007.

Precedentes e evolução do Direito in WAMBIER, Teresa Arruda Alvim (coord.). Direito e Jurisprudência, São Paulo: Ed. Revista dos Tribunais, 2012, p. 41. 
; WAMBIER, Luiz Rodrigues. Anotações sobre o julgamento de processos repetitivos, Revista IOB de Direito Civil e Processual Civil, v. 49, set-out/2007, p. 38 a 45.

; MEDEIROS, Maria Lúcia Lins Conceição. Recursos repetitivos: realização integral da finalidade do novo sistema impõe mais do que a paralisação dos recursos especiais que estão no $2 .^{\circ}$ grau. Revista de Processo. vol. 191. p. 187. São Paulo: Ed. RT, jan. 2011

e outros. A súmula vinculante, vista como meio legítimo para diminuir a sobrecarga de trabalho dos tribunais brasileiros. Revista do Advogado, $\mathrm{n}^{\mathrm{o}}$ 92/2007, Associação dos Advogados de São Paulo.

et. Al, Primeiros comentários ao Novo Código de Processo Civil. São Paulo: Revista dos Tribunais, 2015

AZEVEDO, Álvaro Villaça. Os assentos no direito processual civil in Justitia - Órgão do Ministério Público de São Paulo, no 74, São Paulo, jul./set. 1971.

BAHIA, Alexandre; NUNES, Dierle. Tendências de padronização decisória no PLS 166/2010: o Brasil entre o civil law e o common law e os problemas na utilização do "marco zero interpretativo", in Reforma do processo civil: perspectivas constitucionais. Flaviane de Magalhães Barros; José Luiz de Morais (coordenadores). Belo Horizonte: Fórum, 2010.

; ..Processo, jurisdição e

processualismo constitucional democrático na américa latina: alguns apontamentos Disponível em: http://www.pos.direito.ufmg.br/rbepdocs/101061096.pdf - Acessado em 05.01.2018, p. 86 . 
BARBOSA MOREIRA, José Carlos. A Emenda Constitucional n. 45 e o processo. Temas de Direito Processual Civil (nona série), São Paulo, Saraiva, 2007.

A revolução processual inglesa. Temas de Direito Processual Civil (nona série), São Paulo, Saraiva, 2007.

A Suprema Corte Norte-Americana: um modelo para o mundo?, in Temas de direito processual, $8^{\text {a }}$ série. São Paulo: Saraiva, 2004, pp. 239-251.

Comentários ao Código de Processo Civil, volume 5. 16.

ed. Rio de Janeiro: Forense, 2012.

Correntes e contracorrentes no processo civil contemporâneo. Temas de Direito Processual Civil (nona série), São Paulo, Saraiva, 2007. . Dois cientistas políticos, três economistas e a Justiça Brasileira. Temas de Direito Processual Civil (nona série), São Paulo, Saraiva, 2007. O processo civil brasileiro entre dois mundos. In: Revista da EMERJ, v. 4, n. 16, 2001. . Notas sobre alguns aspectos do processo (civil e penal) nos países anglo-saxônicos, in Revista de Processo, volume 92, São Paulo, Revista dos Tribunais, 1998.

O processo civil contemporâneo: um enfoque comparativo. Temas de Direito Processual Civil (nona série), São Paulo, Saraiva, 2007. . Súmula, jurisprudência, precedente: uma escalada e seus riscos. Temas de Direito Processual Civil (nona série), São Paulo, Saraiva, 2007. 
BARIONI, Rodrigo. The Unpublished Opinions in the American System: Contributions to the "Assunção de Competência. In: Revista de Processo, volume 261. São Paulo: Revista dos Tribunais, 2016,

BARROSO, Luís Roberto. O controle de constitucionalidade no direito brasileiro. São Paulo: Saraiva, 2006 p. 176-177; STRECK, Lênio. Jurisdição constitucional hermenêutica, $2^{\mathrm{a}}$ ed., Rio de Janeiro, Forense, 2004.

BASIL, S. Markensis. Foreign law and comparative methodology: a subject and a thesis. Hart, Oxford, 1997.

BEDAQUE, José Roberto dos Santos. Efetividade do processo e técnica processual. $3^{\mathrm{a}}$ ed. São Paulo: Malheiros, 2010.

BENETI, Sidnei Agostinho. Assunção de competência e fast-track recursal. in Revista de Processo, volume 171, São Paulo, Revista dos Tribunais, 2009.

. Doutrina de precedentes e organização judiciária, in Processo e Constituição: estudos em homenagem ao professor José Carlos Barbosa Moreira. Luiz Fux; Nelson Nery Junior; Teresa Arruda Alvim Wambier (coordenadores). São Paulo: Editora RT, 2006.

BERMUDES, Sérgio. A Reforma do Judiciário pela Emenda Constitucional $n^{o} 45$, Rio de Janeiro, Editora Forense, 2005.

BLACK, Henry Campbell. Black's law dictionary. 3. ed. Minnesota: West Publishing, 1933.

BORNKAMM, Joachim. O Recurso Especial (Revision) $e$ as novas tendências na jurisprudência do Superior Tribunal de Justiça (Bundesgerichtshof), in Cadernos do Centro de Estudos Judiciários, volume 26, pp. 22-23. Disponível em: <http://www.cjf.jus.br/cjf/CEJ-Coedi/gd/documentos/seriecadernoscej26brasilalemanha.pdf>. Acessado em: 05.01.2018. 
BONIZZI, Marcelo José Magalhães. A capacidade postulatória dos advogados perante as Cortes Supremas: perspectivas de direito comparado no Brasil, na França e na Itália. In: Direito Processual Constitucional (Coord: PUOLI, José Carlos Baptista; BONIZZI, Marcelo José Magalhães. LEONEL, Ricardo de Barros. Brasília: Gazeta Jurídica, 2016, 133-134.

BOULOS, Cristhiane. Controle preventivo júrisdicional de constitucionalidade. Critérios para a sua adoção no Brasil (Tese) - Doutorado, Faculdade de Direito da Universidade de São Paulo, São Paulo, 2006.

BUENO, Cássio Scarpinella. Amicus Curiae no processo civil brasileiro: um terceiro enigmático. $3^{\text {a }}$ edição, rev. e atual. São Paulo: Saraiva, 2012.

- Curso sistematizado de direito processual civil, 5 recursos, processos e incidentes nos tribunais, sucedâneos recursais; técnicas de controle das decisões jurisdicionais. São Paulo: Saraiva, 2008.

BUSTAMANTE, Thomas da Rosa. A dificuldade de se criar uma cultura argumentativa do precedente judicial e o desafio do Novo CPC. In: Precedentes. Salvador: JusPodivm, 2015.

. Teoria do precedente judicial: a justificação e aplicação de regras jurisprudenciais. São Paulo: Noeses, 2012

BUZAID, Alfredo. Uniformização da jurisprudência. Sidney Sanchez (autor). São Paulo: Editora RT, 1975.

CABRAL, Antônio do Passo. A escolha da causa-piloto nos incidentes de resolução de processos repetitivos. Revista de Processo. Vol. 231, p. 201, São Paulo: Ed. RT, maio/2014 
- A técnica do julgamento-alerta na mudança de jurisprudência consolidada. In: Revista de Processo, volume 221. São Paulo, Revista dos Tribunais, 2013.

Os efeitos processuais da audiência pública. In: Revista de Direito de Estado. Vol. 2, p. 199, Rio de Janeiro: Renovar, 2006.

. O novo procedimento-modelo (Musterverfahren) alemão:

uma alternativa às ações coletivas. Revista de Processo, Vol. 147. São Paulo: Ed. RT, 2007, p. 130,

CALMON DE PASSOS, José Joaquim. Súmula vinculante. Revista Diálogo Jurídico, $\mathrm{n}^{\mathrm{o}}$ 10, janeiro de 2002. Disponível em www.direitopublico.com.br/pdf_10/DIALOGOJURIDICO-10-JANEIRO-2002-CALMON-DE-PASSOS.pdf, Acesso, 13 de outubro de 2014.

CÂMARA, Alexandre Freitas. O novo processo civil brasileiro. São Paulo: Atlas, 2015

CAMBI, Eduardo. Jurisprudência lotérica, in Revista dos Tribunais, volume 90, São Paulo, Revista dos Tribunais, 2011.

CAPPELETTI, Mauro. Juízes legisladores? Trad. de Carlos Alberto Álvaro de Oliveira do original Giudici legislatori? Porto Alegre, Sérgio Antonio Fabris Editor, 1993.

e GARTH, Bryant. Access to justice: the worldwide movement to make rights effective. A general report (trad. de Ellen Gracie Northfleet: Acesso à Justiça), Porto Alegre, Sérgio Antônio Fabris Editor, 1988.

CARMONA, Carlos Alberto. Quinze anos de reformas no Código de Processo Civil. CARMONA, Carlos Alberto (coord.). Reflexões sobre a reforma do código de processo civil: estudos em homenagem a Ada Pellegrini Grinover, Cândido R. Dinamarco e Kazuo Watanabe. São Paulo: Atlas, 2007. 
CARNEGEM, R. C. van. Oráculos da Lei ou Bouche de la Loi. Considerações Históricas sobre o papel dos juízes, in Instituto de História do Direito e do Pensamento Político. $O$ perfil do juiz na tradição ocidental: Seminário Internacional. Lisboa: Almedina, 2007.

CARVALHO, Mayara; SILVA, Juliana Coelho Tavares. Ressalva de entendimento e valorização da primeira instância no sistema de precedentes brasileiro. In: Precedentes. Salvador: JusPodivm, 2015.

CAZETTA JÚNIOR, José Jesus, Assentos da Casa da Suplicação, in Revista do Advogado, no 84, São Paulo: AASP, 2005.

CHEIM JORGE, Flávio. Embargos de divergência: alguns aspectos estruturais. In Revista de Processo 190. São Paulo, Revista dos Tribunais, 2010.

; DIDIER JÚNIOR, Fredie; RODRIGUES, Marcelo Abelha. A terceira etapa da reforça processual civil: comentários às leis $n .11 .187$ e 11.232, de 2005; 11.276, 11.277 e 11.280, de 2006. São Paulo: Saraiva, 2006.

CIMARDI, Cláudia Aparecida. A jurisprudência uniforme e os precedentes no Novo Código de Processo Civil Brasileiro. São Paulo: Editora Revista dos Tribunais, 2015.

CONSELHO NACIONAL DE JUSTIÇA, A força normativa do direito judicial: uma análise da aplicação prática do precedente no direito brasileiro e dos seus desafios para a legitimação da autoridade do Poder Judiciário. Coord. Thomas da Rosa de Bustamante (et al); Alice Gontijo Santo Teixeira (et al); colab. Gláucio Ferreira Maciel (et al). Brasília: Conselho Nacional de Justiça, 2015.

Justiça em números 2015: ano-base 2014, Brasília:

Conselho Nacional de Justiça, 2015.

COELHO, Gláucia Mara. Repercussão geral: da questão constitucional no processo civil brasileiro. São Paulo: Atlas, 2009. 
COLE, Charles D. Precedente Judicial: a experiência norte americana, in Revista de Processo, volume 23, São Paulo, Revista dos Tribunais, 1998.

CÔRTES, Osmar Mendes Paixão, A experiência brasileira com a vinculação das decisões judiciais e a atual súmula vinculante introduzida pela EC 45/2004, in Direito civil e processo - Estudos em homenagem ao Professor Arruda Alvim, 2007.

CUNHA, Leonardo José Carneiro da. O regime processual das causas repetitivas, in Revista de Processo, vol. 179, São Paulo, Revista dos Tribunais, 2010.

CRUZ E TUCCI, José Rogério. A 'repercussão geral' como pressuposto de admissibilidade do recurso extraordinário, São Paulo, in RePro 848, São Paulo, Revista dos Tribunais, 2006.

. Anotações sobre a 'repercussão geral' como pressuposto de admissibilidade do recurso extraordinário (Lei 11.418/2006), Terceira etapa da reforma do Código de Processo Civil - Estudos em homenagem ao Ministro José Augusto Delgado. Obra coletiva organizada por Adriano Caldeira e Rodrigo da Cunha Lima Freire, Salvador, Editora Podvm, 2007.

(Coord). Direito processual civil europeu contemporâneo. São Paulo: Lex Editora, 2010.

(Coord). Direito processual civil americano contemporâneo São Paulo: Lex Editora, 2010. - Eficácia do precedente judicial na história do direito brasileiro, in Revista do Advogado, no 78, São Paulo, AASP, set. 2004. . Precedente judicial como fonte de direito, São Paulo: Revista dos Tribunais, 2004. 
Parâmetros de eficácia e critérios de interpretação do precedente judicial. in WAMBIER, Teresa Arruda Alvim (coord.). Direito e Jurisprudência, São Paulo: Ed. Revista dos Tribunais, 2012

CUNHA, Leonardo Carneiro. Causas repetitivas e a necessidade de um regime que lhes seja próprio, Disponível em: https://www.fdsm.edu.br/posgraduacao/revista_artigo.php?artigo=40\&volume= Acessado em 05.01.2018.

DALLARI, Dalmo de Abreu. O poder dos juízes, $3^{\mathrm{a}}$ edição, São Paulo, Saraiva, 2007.

DAVID, René. Os grandes sistemas do Direito Contemporâneo (trad. Hermínio A. Carvalho), 4a ed., São Paulo: Martins Fontes, 2002.

DIDIER JR., Fredie. A terceira etapa da reforma processual civil, São Paulo, Saraiva, 2006.

Sistema brasileiro de precedentes judiciais obrigatórios $e$ os deveres institucionais dos tribunais: uniformidade, estabilidade, integridade $e$ coerência da jurisprudência. In: Precedentes. Salvador: JusPodivm, 2015

Transformações do recurso extraordinário, in Aspectos polêmicos e atuais dos recursos cíveis e assuntos afins, volume 10. Nelson Nery Junior; Teresa Arruda Alvim Wambier (coordenação). São Paulo: Editora RT, 2006.

DINAMARCO, Cândido Rangel. A instrumentalidade do processo, $14^{\mathrm{a}}$ edição, São Paulo, Malheiros, 2009. . A reforma do Código de Processo Civil, $3^{\mathrm{a}}$ edição, São

Paulo, Malheiros, 2001. A reforma da reforma. $3^{\text {a }}$ edição, revista e atualizada, São Paulo, Malheiros, 2002. 
. Fundamentos do processo civil moderno, tomo I. 6. ed.

São Paulo: Malheiros, 2010.

. Instituições de Direito Processual Civil. Vol. I, $6^{\text {a }}$ edição,

revista e atualizada, São Paulo: Malheiros, 2009

O relator, a jurisprudência e os recursos, Aspectos

polêmicos e atuais dos recursos cíveis de acordo com a Lei 9.756/98. Obra coletiva coordenada por Teresa Arruda Alvim Wambier e Nelson Nery Jr., São Paulo, Revista dos Tribunais, 1999.

. Instituições de Direito Processual Civil. Vol. I, $6^{\text {a }}$ edição, revista e atualizada, São Paulo: Malheiros, 2009.

; LOPES, Bruno Vasconcelos Carrilho. Teoria Geral do

Novo Processo Civil: De acordo com a Lei 13.256, de 04.02.2016. São Paulo: Malheiros, 2016.

DUXBURY, Neil. The nature and authority of precedent. New York: Cambridge University Press, 2008.

DWORKIN, Ronald. Law's empire (tradução de Jefferson Luiz Camargo: O império do Direito), São Paulo, Martins Fontes, 1999.

Levando os direitos a sério. São Paulo : Manins Fontes,

2002

FARBER, Daniel A. The Rule of Law and the Law of Precedents, Minnesota Law Review 90, n. 5, 1173-203, May 2006.

FERNANDES, Ernesto. RÊGO, Anibal. Súmula das lições proferidas pelo Marcelo Caetano ao curso do $1^{o}$ ano jurídico de 1940-41 na Faculdade de Direito de Lisboa. Lisboa : Imprensa Baroeth, 1941. 
FERRAZ, Ricardo de Barros Falcão. Motivação política no precedente judicial, in Revista de Processo, volume 200, São Paulo, Revista dos Tribunais, 2011.

FERREIRA DA SILVA, Luis Renato. A regra do precedente no direito inglês, in Revista de Direito Civil, volume 75, São Paulo, Revista dos Tribunais, 1996.

FLOYD, Daisy Hurst. Candor versus Advocacy: Court's use of santions to enforce the duty of candor toward the tribunal, Georgia Law Review, 1035, 1994-1995. Disponível em: https://ttu-ir.tdl.org/ttu-ir/bitstream/handle/10601/556/dfloyd5.pdf?sequence=1 - Acessado em 05.01.2018.

FUX, Luiz. A desistência recursal e os recursos repetitivos. Disponível em http://bdjur.stj.jus.br/jspui/bitstream/2011/27102/Desist\%C3\%AAncia_Recursal_Recursos. doc.pdf - Acessado em 25.06.2016

GAIO JÚNIOR, Antônio Pereira. Predicados da súmula vinculante: objeto, eficácia e outros desdobramentos, in Revista de Processo, volume 207, São Paulo, Revista dos Tribunais, 2012.

GALDIANO, José Eduardo Berto. Técnica de julgamento de recursos repetitivos pelo Supremo Tribunal Federal e pelo Superior Tribunal de Justiça (Dissertação) - Mestrado, Faculdade de Direito da Universidade de São Paulo, São Paulo, 2014.

GARCIA, Gustavo Filipe Barbosa. Reforma trabalhista restringe atuação da jurisprudência dos Tribunais do Trabalho. Disponível em: http://gustavogarcia.adv.br/ - Acessado em 05.01.2018).

GERHARDT, Michael J. The power of precedent. New York: Oxford University Press, 2008

Super Precedent, Minnesota Law Review 90, n 5, 1204-

31, May 2006. 
GOODHART, Arthur L. Three cases on possession. The Cambridge Law Journal, n. 3, 1928, p. 195-208.

Three cases on possession. The Cambridge Law Journal,

n. 3,1928

GRINOVER, Ada Pellegrini. Ensaio sobre a processualidade: fundamentos para uma nova teoria geral do processo. Brasília: Gazeta Jurídica, 2016.

HARRIS, J.W. Towards Principles of Overruling-When Should a Final Court of Appeal Second Guess? In: Oxford Journal of Legal Studies, Volume 10, Edição 2, Julho de 1990.

HERTEL, Christian. Legal systems of the world. An overview. Notarius International. 12/2009. Disponível em: http://www.notariusinternational.uinl.org/database/2009/notarius_2009_01_02_hertel_en.pdf - Acessado em: 05.01 .2018

JULIANI, Cristiano Reis. A nova redação do art. 555, do CPC e a uniformização de jurisprudência. Disponível em http://www.planalto.gov.br/ccivil_03/revista/rev_73/artigos/Cristiano_rev73.htm Acesso em 14 de outubro de 2014.

GILMORE, Angela. Self-Inflicted Wounds: The Duty to Disclose Damaging Legal Authority, 43 Cleveland Law Review, 303, 1995.

KERN, Christoph; STÜRNER, Rolf. Processo civil comparado - Tendências recentes e fundamentais, in Revista de Processo, volume 200, São Paulo, Revista dos Tribunais, 2011.

KOMÁREK, Jan. Reasoning with Previous Decisions: Beyond the Doctrine of Precedent. LSE Legal Studies Working Paper No. 8/2012, p. 170. 
KRISLOV, Samuel.The amicus curiae brief: from friendship to advocacy. The Yale Law Journal, vol. 72, n. 4, p. 694-721, mar/1963

LARENZ, Karl. Metodologia da ciência do direito. 2. Ed. Tradução de José de Souza Brito e José Antonio Veloso. Lisboa: Fundação Calouste Gulbekian, 1969.

LASPRO, Oreste Nestor de Souza. O objeto dos embargos de divergência. In: Revista de Processo 186. São Paulo, Revista dos Tribunais, 2010.

LEAL, Victor Nunes. Atualidade do Supremo Tribunal Federal, Revista Forense, Rio de Janeiro, Forense, v. 208, 1964.

Passado e futuro da súmula do STF. In: Revista de Direito Administrativo, Rio de Janeiro, Renovar, n. 145, p. 1-20, jul-set, 1981

LEONEL, Ricardo de Barros. Direito Processual Civil Francês in: Direito processual civil europeu contemporâneo. José Rogério Cruz e Tucci (coordenador). São Paulo: Lex Editora, 2010, p. 139-140

Notas a respeito da valorização dos precedentes no novo CPC. Artigo no prelo, cedido pelo autor.

- Reclamação constitucional. São Paulo: Revista dos

Tribunais, 2011

LESSA, Pedro. Do Poder Judiciário. Rio de Janeiro: Francisco Alves, 1915

LIMA, Tiago Asfor Rocha. Precedentes judiciais civis. São Paulo: Saraiva, 2013.

LORD WOOLF. Access do Justice - Final Report (Final Report to the Lord Chancellor on the civil justice system in England and Wales). Disponível em www.dca.gov.uk/civil/final/intro.htm Acesso em 12 de outubro de 2014. 
LUCCA, Rodrigo Ramina. O dever de motivação das decisões judiciais. Salvador: JusPodium, 2015, p. 125.

LUCON, Paulo Henrique dos Santos. Devido processo legal substancial in Leituras complementares de processo civil. Fredie Didier Júnior (organizador). 5. ed. Salvador: Editora Jus Podivm, 2007.

MACCORMICK, Neil; SUMMERS, Robert S. Introduction, in: Interpreting precedents. A comparative study. New York: Routledge, 1997.

MACÊDO, Lucas Buril de. Contributo para a definição de ratio decidendi na teoria brasileira dos precedentes judiciais, in DIDIER JR., Fredie (coord.). Precedentes, Salvador: Ed. Jus Podium, 2015.

Reclamação constitucional e precedentes obrigatórios.

Revista de Processo, v. 238, p. 413-434, 2014

MALLET, Estevão. Reflexões sobre a Lei 06 n. 13.015/2014, Disponível em: http://mallet.adv.br/artigo-2-lei-n-13015-revista-do-tst/ - Acessado em 05.01.2018

MANCUSO, Rodolfo de Camargo. A realidade judiciária brasileira e os Tribunais da Federação - STF e STJ: inevitabilidade de elementos de contenção dos recursos a eles dirigidos. Processo e Constituição. Obra coletiva coordenada por Luiz Fux, Nelson Nery Jr. e Teresa Arruda Alvim Wambier, Revista dos Tribunais, São Paulo, 2006.

Divergência jurisprudencial e súmula vinculante. 4. ed.

São Paulo: Ed. RT, 2010.

Questões controvertidas sobre a súmula vinculante, in

Os poderes do juiz e o controle das decisões judiciais. Coordenação: José Miguel Garcia Medina et al. São Paulo: Editora Revista dos Tribunais, 2008. 
Recurso extraordinário e recurso especial. $11^{\mathrm{a}}$ edição, revista, atualizada e ampliada. São Paulo: Editora Revista dos Tribunais, 2010.

. Sistema Brasileiro de Precedentes: natureza, eficácia, operacionalidade. São Paulo: Editora Revista dos Tribunais, 2014.

MARCATO, Antonio Carlos. Algumas considerações sobre a crise da Justiça, p. 18. Disponível em: $\quad$ http://www.marcatoadvogados.com.br/wpcontent/uploads/2015/07/arquivo66.pdf - Acessado em 22.06.2015.

. (Coord.) Código de Processo Civil interpretado, 3. ed.

São Paulo, Atlas, 2008.

Crise da justiça e influência dos precedentes judiciais no direito processual civil brasileiro, 2009. Tese (Professor Titular de Direito Processual Civil) - Faculdade de Direito da Universidade de São Paulo, São Paulo, 2009.

MARINHO, Hugo Chacra Carvalho e. Fatores para a identificação dos precedentes com eficácia vinculante (Dissertação) - Mestrado, Faculdade de Direito da Universidade de São Paulo, São Paulo, 2017

MARINONI, Luiz Guilherme (coordenador). A Força dos Precedentes. Editora Jus Podivm, 2012.

. Precedentes obrigatórios. São Paulo: Editora Revista dos

Tribunais, 2010 .

. Uma nova realidade diante do Projeto de CPC: a ratio decidendi ou os fundamentos determinantes da decisão. in: Revista dos Tribunais, volume 101, n. 918, São Paulo, Revista dos Tribunais, abril de 2012

Sobre o incidente de assunção de competência. In:

Revista de Processo, volume 260. São Paulo, Revista dos Tribunais, 2016 
- Eficácia temporal da revogação da jurisprudência consolidada dos Tribunais Superiores, p. 17. Disponível em http://www2.senado.leg.br/bdsf/handle/id/242857. Acessado em 05.01.2008 ; MITIDIERO, Daniel. Repercussão geral no recurso extraordinário. São Paulo: Editora RT, 2007.

O projeto do novo

CPC. $1^{\text {a }}$ Ed. São Paulo: RT, 2010, p.170.

MAUROIS, André. História da Inglaterra. Tradução de Carlos Domingues. Rio de Janeiro: Irmãos Pongetti, 1959.

MAXIMILIANO, Carlos. Hermenêutica e aplicação do direito. Rio de Janeiro: Forense, 2010.

MEDINA, José Miguel Garcia. O prequestionamento nos recursos extraordinário e especial. Recursos no processo civil - 6. 4. ed. São Paulo: Editora RT, 2010.

; WAMBIER, Luiz Rodrigues; WAMBIER, Teresa Arruda Alvim. Breves comentários à nova sistemática processual civil 2. São Paulo: Editora RT.

Repercussão geral e súmula vinculante - Relevantes novidades trazidas pela EC 45/2004, in Reforma do Judiciário: primeiras reflexões sobre a emenda constitucional 45/2004. Teresa Arruda Alvim Wambier et. al. (coordenação). São Paulo: Editora RT, 2005.

MENDES, Aluisio Gonçalves de Castro. Precedente e IRDR: Algumas considerações. In: Precedentes. Salvador: JusPodivm, 2015.

- Precedentes e jurisprudência: papel, fatores $e$ perspectivas no direito brasileiro contemporâneo. In Direito Jurisprudencial, vol. 2. 
Coordenação: Aluísio Gonçalves de Castro Mendes, Luiz Guilherme Marinoni, Teresa Arruda Alvim Wambier. São Paulo: Editora Revista dos Tribunais, 2014.

; SILVA, Larissa Clare Pochmann. Precedente e IRDR: algumas considerações. In: Precedentes. Salvador: JusPodivm, 2015

MENDES, Gilmar Ferreira, Curso de direito constitucional. $7^{\mathrm{a}}$ ed. rev. e. atual.. São Paulo: Saraiva, 2012, p. 1471.

; PFLUG, Samantha Meyer. Passado e futuro da súmula vinculante: considerações à luz da Emenda Constitucional n. 45/2004, Reforma do Judiciário, Obra coletiva coordenada por Sérgio Rabelo Tamm Renault e Pierpaolo Bottini, São Paulo, Saraiva, 2005.

MENEZES MARCATO, Ana Cândida. Contornos da repercussão geral, o novo requisito de admissibilidade do recurso extraordinário, Reflexões sobre a Reforma do Código de Processo Civil - Estudos em homenagem a Ada Pellegrini Grinover, Cândido Rangel Dinamarco e Kazuo Watanabe. Obra coletiva coordenada por Carlos Alberto Carmona, São Paulo, Atlas, 2007.

MENEZES VIGLIAR, José Marcelo. A reforma do judiciário e as súmulas de efeitos vinculantes. Reforma do Judiciário analisada e comentada. Obra coletiva coordenada por André Ramos Tavares, Pedro Lenza e Pietro de Jesús Lora Alarcón. São Paulo, Editora Método, 2005.

Uniformização de jurisprudência - Segurança jurídica e dever de uniformizar, São Paulo, Atlas, 2003.

MERRYMEN, John Henry; PÉREZ-PERDOMO, Rogelio. A tradição da civil law. Uma introdução aos sistemas jurídicos da Europa e da América Latina. Tradução de Cássio Casagrande. Porto Alegre: Fabris, 2009. 
MIGUEL, Alfonso Ruiz; LAPORTA, Franciso J. Precedent in Spain. In: Interpreting precedents. A comparative study. New York: Routledge, 1997

MITIDIERO, Daniel. Por uma reforma da Justiça Civil no Brasil. Um diálogo entre Mauro Cappelletti, Vittorio Denti, Ovídio Baptista e Luiz Guilherme Marinoni, in Revista de Processo, volume 199, São Paulo, Revista dos Tribunais, 2011.

MONNERAT, Fábio Victor da Fonte. Primeiras aplicações do art. 285-A do CPC, in Revista de Processo, volume 157, ano 33, março de 2008.

A jurisprudência uniformizada como estratégia de aceleração do procedimento, in Direito Jurisprudencial. Teresa Arruda Alvim Wambier, coordenação. São Paulo: Editora Revista dos Tribunais, 2012.

MORETO, Mariana Capela Lombardi. O precedente judicial no sistema processual brasileiro (Tese) - Doutorado, Faculdade de Direito da Universidade de São Paulo, São Paulo, 2012.

MUSCARI, Marco Antonio Botto. Súmulas vinculantes. São Paulo: Juarez de Oliveira, 1999.

Teoria dos recursos repetitivos: Tutela pluri-individual nos recursos dirigidos ao STF e ao STJ. $1^{\mathrm{a}}$ ed. São Paulo: Ed. RT, 2014.

NAVES, Nilson Vital. O Supremo, o Superior Tribunal e a reforma. Disponível em http://bdjur.stj.jus.br/dspace/bitstream/2011/1885/1/ Acesso 10 de outubro de 2014.

NEGRÃO, Theotonio; GOUVÊA, José Roberto Ferreira; BONDIOLI, Luis Guilherme Aidar; FONSECA, João Francisco Naves da (colaboração). Código de Processo Civil e Legislação Processual em Vigor. 42. ed. São Paulo: Saraiva, 2010. 
NERY JUNIOR, Nelson. Princípios do Processo Civil na Constituição Federal - Coleção Estudos de Direito de Processo Civil Professor Enrico Tullio Liebman; 21. 8. ed. São Paulo: Editora Revista dos Tribunais, 2004.

; NERY, Rosa Maria de Andrade. Código de Processo Civil comentado e legislação extravagante. 9. ed. São Paulo: Editora RT, 2006.

; NERY. Rosa Maria de Andrade. Comentários ao Código de Processo Civil. São Paulo: RT, 2015, p. 1837);

; ABBOUD, Georges, "Núcleo duro do novo CPC é inconstitucional", diz jurista. Disponível em: https://www.jota.info/justica/nucleo-duro-

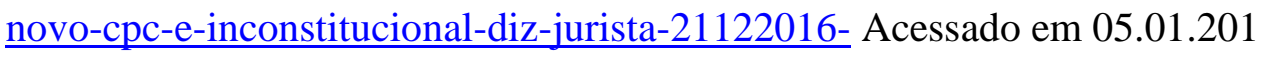

NUNES, Dierle. Precedentes, padronização decisória preventiva e coletivização. in Direito Jurisprudencial. Teresa Arruda Alvim Wambier, coordenação. São Paulo: Editora Revista dos Tribunais, 2012

- Processualismo constitucional democrático $e \quad o$ dimensionamento de técnicas para a litigiosidade repetitiva: a litigância de interesse público e as tendências "não compreendidas" de padronização decisória. Revista de Processo, ano 36, vol. 199, set/2011

OLIVEIRA, Guilherme José Braz de. Nova técnica de julgamento de casos repetitivos à luz do Novo Código de Processo Civil: O incidente de resolução de demandas repetitivas (Tese) - Doutorado, Faculdade de Direito da Universidade de São Paulo, São Paulo, 2015.

OLIVEIRA, Pedro Miranda. A força das decisões judiciais. In: Revista de Processo, Volume 216, São Paulo, Revista dos Tribunais, 2013.

O binômio repercussão geral e súmula vinculante: necessidade da aplicação conjunta dos dois institutos, in Direito Jurisprudencial. Teresa Arruda Alvim Wambier, coordenação. São Paulo: Editora Revista dos Tribunais, 2012. 
PARENTE, Eduardo de Albuquerque. Jurisprudência - Da divergência à uniformização. Coleção Atlas de Processo Civil, coordenação de Carlos Alberto Carmona, São Paulo, Atlas, 2006.

PECZENIK, Aleksander. The binding force of precedent. In: MACCORMICK, Neil; SUMMERS, Robert S. (Orgs.). Interpreting precedents. A comparative study. New York: Routledge

PEREZ, Bruno Leandro Palhares. Análise crítica do modelo brasileiro de acesso aos Tribunais Superiores: A admissibilidade dos recursos excepcionais no Direito Processual Civil brasileiro (Dissertação) - Mestrado, Faculdade de Direito da Universidade de São Paulo, São Paulo, 2016.

PIGNATARI, Alessandra Aparecida Calvoso Gomes. Efeitos processuais no controle judicial de constitucionalidade. Brasília: Gazeta Jurídica, 2014

PORTO, Sérgio Gilberto. Sobre a common law, civil law e o precedente judicial. Estudos de Direito Processual Civil. Obra coletiva coordenada por Luiz Guilherme Marinoni, São Paulo, Revista dos Tribunais, 2005.

POSNER, Richard A. Problemas de filosofia do direito. Tradução de Jefferson Luiz Camargo; revisão técnica e da tradução por Mariana Mota Prado. São Paulo, Martins Fontes, 2007. . How Judges Think. Cambridge: Havard University Press, 2010.

PUOLI, José Carlos Baptista. Precedentes vinculantes? O CPC “depois" da lei $n$. 13.256/16. In: Processo em Jornadas. LUCON, Paulo Henrique dos Santos et alli. (Coord.). Salvador: JusPodivm, 2016 
RAATZ, Igor. Considerações históricas sobre as diferenças entre common law e civil law. Reflexos iniciais para o debate sobre a adoção de precedentes no direito brasileiro, in Revista de Processo, Ano 36, vol. 199, setembro de 2.011.

RAMIRES, Maurício. Crítica à aplicação dos precedentes no direito brasileiro. Porto Alegre: Livraria do Advogado, 2010.

RAMOS, Elival da Silva. O controle de constitucionalidade. In: YARSHELL, Flávio Luiz; MORAES, Maurício Zanoide (Orgs.). Estudos em homenagem à professora Ada Pellegrini Grinover. São Paulo: DPJ Editora, 2005

RAZABONI, Olívia Ferreira. Amicus Curiae: democratização da jurisdição constitucional (Dissertação) - Mestrado, Faculdade de Direito da Universidade de São Paulo, São Paulo, 2009.

RE, Eduard D. Stare decisis. Tradução de Ellen Gracie Northfleet. Revista Forense 327/38, Rio de Janeiro: Forense, junho-setembro de 1994.

RE, Richard M. Narrowing Supreme Court Precedent from Below. in: UCLA School of Law Research Paper No. 15-51.

REHNQUIST, William H. The Supreme Court. New York: Alfred A. Knopf, 2004

RODRIGUEZ, Victor Gabriel. Argumentação jurídica: técnicas de persuasão e lógica informal. 4. ed. São Paulo: Martins Fontes, 1995.

ROCHA, Carmen Lúcia Antunes. Sobre a súmula vinculante. Revista de Informação Legislativa, Brasília, v. 34, n. 133, p. 51-64, 1997. Disponível em: http://www2.senado.leg.br/bdsf/bitstream/handle/id/193/r133-06.PDF?sequence=4 Acessado em 05.01.2018. 
RODRIGUES, Marcelo Abelha, Sistema de precedentes ou meros filtros redutores de demandas repetitivas? angústias e desconfianças. In: Revista de Processo, vol. 259, São Paulo, Revista dos Tribunais, 2016

RODRIGUES, Roberto de Aragão Ribeiro. As ações-teste na Alemanha, Inglaterra e legislação brasileira projetada. Disponível em: http://www.agu.gov.br/page/download/index/id/9923690 - Acessado em 05.01.2018.

ROSA, Renato Xavier da Silveira Rosa. Precedentes Judiciais em perspectiva: Contribuição para a análise econômica dos precedentes na ciência processual civil brasileira. In: Revista do Instituto dos Advogados de São Paulo, volume 33, São Paulo, Revista dos Tribunais, 2014. . Precedentes no processo civil brasileiro: valorização e efetividade (Dissertação) - Mestrado, Faculdade de Direito da Universidade de São Paulo, São Paulo, 2013.

ROSS, Alf. On Law and Justice (tradução de Edson Bini: Direito e Justiça), São Paulo, EDIPRO, 2000.

ROSSI, Júlio César. O precedente à brasileira: Súmula Vinculante e o incidente de resolução de demandas repetitivas, in Revista de Processo, vol. 208, São Paulo, Revista dos Tribunais, 2012.

SACCO, Rodolfo. Legal Formants: A Dynamic Approach to Comparative Law. In: The American Journal of Comparative Law, Volume 39, Issue 2.

SALLES, Carlos Alberto. Precedentes e jurisprudência no Novo CPC: Novas Técnicas Decisórias? In: O Novo Código de Processo Civil - Questões Controvertidas. São Paulo: Atlas, 2015.

SANCHES, Sydney. Argüição de relevância da questão federal, in: Revista dos Tribunais, volume 627, São Paulo, Revista dos Tribunais, 1988. 
SANTOS, Evaristo Aragão. Em torno do conceito e da formação do precedente judicial. in Direito Jurisprudencial. Teresa Arruda Alvim Wambier, coordenação. São Paulo: Editora Revista dos Tribunais, 2012.

SEPÚLVEDA PERTENCE, José Paulo. Jurisdição constitucional, decisões judiciais vinculantes e direitos fundamentais, Jurisdição constitucional e direitos fundamentais. Obra coletiva coordenada por José Adaércio Leite Sampaio, Belo Horizonte, Del Rey, 2003.

SHANNON, Bradley Scott. May Stare Decisis Be Abrogated by Rule? Ohio State Law Journal 67, n 3, 645-92, 2006.

SCHAUER, Frederick. Precedent. in: Stanford Law Review. Vol. 39, $\mathrm{n}^{\mathbf{o}}$. 3, Fevereiro/1987.

SCHMITZ, Leonard Ziesemer. Por que fundamentar, o que fundamentar e como (não) fundamentar no CPC/15 - Disponível em: https://www.academia.edu/32255593/Por_que_fundamentar_o_que_fundamentar_e_como _n\%C3\%A3o_fundamentar_no_CPC_15 - Acessado em 05.01.2018

SICA, Heitor Vitor Mendonça. Direito Processual Civil Espanhol in: Direito processual civil europeu contemporâneo. José Rogério Cruz e Tucci (coordenador). São Paulo: Lex Editora, 2010

SIMARD, Linda Sandstorm. An empirical study of amicus curiae in Federal Court: a fine balance of access, efficiency, and adversarialism. Suffolk University Law School, Legal Studies Research Paper Series, p. 07-34, set/2007

SILVA, Ana de Lourdes Coutinho. Estudo da motivação das decisões judiciais no século da jurisdição: uma reavaliação do momento jurisprudencial do direito (Tese) - Doutorado, Faculdade de Direito da Universidade de São Paulo, São Paulo, 2010. 
SILVA SOARES, Guido Fernando. Common law - Introdução ao Direito nos EUA, São Paulo, RT, 1999.

SILVA, José Afonso da. Do Recurso Extraordinário no Direito Processual Brasileiro. São Paulo: RT, 1963

SILVA, Virgilio Afonso. O STF e o controle de constitucionalidade: deliberação, diálogo e razão pública, p. $207 \quad$ - $\quad$ Disponível em: http://bibliotecadigital.fgv.br/ojs/index.php/rda/article/view/4144/2927 - Acessado em 05.01.2018.

SINCLAIR, Michael. Precedent, Super-Precedent. Disponível em http://law.bepress.com/cgi/viewcontent.cgi?article=6752\&context=expresso - Acessado em 05.01.2018.

SOUZA, Arthur César. Resolução de demandas repetitivas. São Paulo: Almedina, 2015.

SOUZA, Michel Roberto Oliveira de. Recurso especial repetitivo: Análise crítica do julgamento por amostragem (Dissertação de mestrado). São Paulo: Universidade de São Paulo, 2014.

STRECK, Lenio Luiz. O efeito vinculante das súmulas e o mito da efetividade: uma crítica hermenêutica. Constituição e democracia - Estudos em homenagem ao Professo J.J. Gomes Canotilho. Obra coletiva coordenada por Paulo Bonavides, Francisco Gérson Marques de Lima e Fayga Silveira Bedê. São Paulo, Malheiros, 2006.

. Súmulas no direito brasileiro. Eficácia, poder e função:

a ilegitimidade constitucional do efeito vinculante. Porto Alegre: Livraria do Advogado, 1998.

; ABBOUD, Georges. O que é isto - o precedente judicial e as súmulas vinculantes? 2a ed. Porto Alegre: Livraria do Advogado, 2014, p. 63. 
${ }^{1}$ A força normativa do direito judicial: uma análise da aplicação prática do precedente no direito brasileiro e dos seus desafios para a legitimação da autoridade do Poder Judiciário. Coord. Thomas da Rosa de Bustamante (et al); Alice Gontijo Santo Teixeira (et al); colab. Gláucio Ferreira Maciel (et al). Brasília: Conselho Nacional de Justiça, 2015

SUMMERS, Robert S. Precedent in the United States (New York State). In: Interpreting precedents. A comparative study. New York: Routledge, 1997.

TALAMINI, Eduardo. Comentários ao art. 138. In: WAMBIER, Teresa Arruda Alvim; DIDIER JR., Fredie; TALAMINI, Eduardo; DANTAS, Bruno (Coords.). Breves Comentários ao novo Código de Processo Civil. São Paulo: Revista dos Tribunais, 2015, p. 439.

TARUFFO, Michele Icebergs do common law $e$ civil law? Macrocomparação $e$ microcomparação processual e o problema da verificação da verdade. In: Revista de Processo, nº 181, trad.: Hermes Zanetti Júnior, São Paulo, Revista dos Tribunais, 2010.

- Institutional factors influencing precedents. In: Interpreting precedents: a comparative study (obra coletiva), org. D. Neil MacCormick e Robert S. Summers, Aldershot e Vermont, Dartmouth e Ashgate, 1997.

Observações sobre os modelos processuais de civil law e de common law. In: Revista de Processo, volume 110, trad: José Carlos Barbosa Moreira, São Paulo, Revista dos Tribunais, 2003.

Precedente e jurisprudência, in Revista de Processo, vol. 199, São Paulo, Revista dos Tribunais, 2011.

Senso comum, experiência e ciência no raciocínio do Juiz. In: revista Forense, vol. 355, trad. port. Cândido Rangel Dinamarco, rev. Luiz Felipe Duarte Martins Costa, Rio de Janeiro, Editora Forense, 2001. 
TAVARES, André Ramos. A repercussão geral no recurso extraordinário. Reforma do Judiciário analisada e comentada. Obra coletiva coordenada por André Ramos Tavares, Pedro Lenza e Pietro de Jesús Lora Alarcón. São Paulo, Editora Método, 2005.

Nova lei da súmula vinculante. São Paulo, Editora

Método, 2007.

Regime da Súmula vinculante, São Paulo, Carta Forense, ano II. No 20, dezembro/janeiro, 2004/2005.

; LA TORRE, Massimo. Precedent in Italy. In: Interpreting precedents. A comparative study. New York: Routledge, 1997

TEIXEIRA, Sálvio de Figueiredo. Da jurisprudência predominante, da uniformização da jurisprudência uniforme, in Revista de Jurisprudência do Tribunal de Justiça de Mato Grosso do Sul, volume 6, número 21, janeiro-fevereiro de 1984.

TEMER, Sofia. Incidente de Resolução de Demanda Repetitivas, Salvador, Ed. Juspodivm, 2016.

TESHEINER, José Maria. Inconstitucionalidades gritantes no artigo 927 do novo CPC. Disponível em http://www.tex.pro.br/index.php/artigos/317-artigos-set-2015/7376inconstitucionalidades-gritantes-no-artigo-927-do-novo-cpc. Acessado em 04.07.2016.

THE NATIONAL LAW JOURNAL. Estados Unidos da América: Aaron S. Bayer, 01.11.2008.

THEODORO JÚNIOR, Humberto. A onda reformista do direito positivo e suas implicações com o princípio da segurança jurídica. Terceira etapa da reforma do Código de Processo Civil. Obra coletiva organizada por Adriano Caldeira e Rodrigo da Cunha Lima Freire, $1^{\text {a }}$ edição, Salvador, Editora Podvm, 2007.. 
Alguns reflexos da emenda constitucional 45, de 08.12.2004, sobre o processo civil. In: Revista de Processo, volume 125, São Paulo, Revista dos Tribunais, 2005.

O novo artigo 543-C do Código de Processo Civil (Lei $n^{o}$ 11.672, de 08.05.2008), Revista IOB de Direito Civil e Processual Civil, São Paulo, IOB Informações Objetivas Publicações Jurídicas Ltda., São Paulo, nº 53, maio/junho 2008.

- Repercussão geral no recurso extraordinário (Lei $n^{o}$ 11.418) e súmula vinculante do Supremo Tribunal Federal (Lei $\left.n^{o} 11.417\right)$. Revista IOB de Direito Civil e Processual Civil, São Paulo, IOB Informações Objetivas e Publicações Jurídicas Ltda., São Paulo, nº 48, jul/ago 2007.

TROPER, Michel; GRZEGORCZYK, Christophe. Precedent in France. In: Interpreting precedents. A comparative study. New York: Routledge, 1997.

TOFFOLI, Vitor. Recursos especiais repetitivos: Critérios de seleção dos recursos paradigmas. Revista de processo. vol. 197. São Paulo: Ed; RT, Jul: 2011.

TOSTES, Natacha Nascimento Gomes. Uniformização da jurisprudência, in Revista de Processo, volume 104, ano 26, outubro-dezembro de 2011.

VOLPE CAMARGO, Luiz Henrique. A motivação dos julgamentos dos Tribunais de $2^{o}$ grau na visão do Superior Tribunal de Justiça: acórdão completo ou fundamentado?, in Revista de Processo, volume 162, São Paulo, Revista dos Tribunais, 2008.

A força dos precedentes no moderno processo civil brasileiro, in Direito Jurisprudencial. Teresa Arruda Alvim Wambier, coordenação. São Paulo: Editora Revista dos Tribunais, 2012.

WAMBIER, Luiz Rodrigues. Uma proposta em torno do conceito de jurisprudência dominante, in Revista de Processo, volume 100, ano 25, outubro-dezembro de 2000. 
; VASCONCELOS, Rita de Cássia Corrêa de. Recursos especiais repetitivos: reflexos das novas regras (Lei 11.672/2008 e Resolução 8 do STJ) nos processos coletivos. Revista de processo. vol. 163. p. 28. São Paulo: Ed. RT, set. 2008.

WATANABE, Kazuo. Relação entre demanda coletiva e demandas individuais. In: Revista de Processo, vol. 139.

WIEACKER, Franz. História do direito privado moderno. 3. ed. Lisboa: Fundação Calouste Gulbenkian, 1980.

YOSHIKAWA, Eduardo Henrique de Oliveira. Recursos no Direito Processual Civil norte-americano, in Revista de Processo, volume 221, julho de 2013.

ZACLIS, Lionel. Direito Processual Civil Estadunidense. in TUCCI, José Rogério Cruz e (coord.). Direito Processual Civil Americano Contemporâneo, São Paulo: Lex Editora, 2010.

ZANETTI JÚNIOR, Hermes. O valor vinculante dos precedentes: teoria dos precedentes normativos formalmente vinculantes. $2^{\text {a }}$ edição, rev. e atual. Salvador: JusPodium, 2015. Precedentes (treat like cases alike) e o Novo Código de Processo Civil. Revista de Processo, volume 235. São Paulo: Revista dos Tribunais, 2014.

ZUFELATO, Camilo. Precedentes judiciais vinculantes à brasileira no Novo CPC: aspectos gerais. In: O Novo Código de Processo Civil: questões controvertidas. São Paulo: Atlas, 2015 